\title{
Need to Make People Believe Science-Science Is Reliable and Means Truth
}

\author{
Wangui Patrick Mwangi \\ Department of Mathematics and Computer Science, University of Eldoret, Eldoret, Kenya \\ Email: patrickmwangi72@yahoo.com, kheteroskedasticity@gmail.com
}

How to cite this paper: Mwangi, W.P. (2019) Need to Make People Believe Science-Science Is Reliable and Means Truth. Open Journal of Social Sciences, 7, 272-287. https://doi.org/10.4236/jss.2019.77024

Received: May 21, 2019

Accepted: July 26, 2019

Published: July 29, 2019

Copyright $\odot 2019$ by author(s) and Scientific Research Publishing Inc. This work is licensed under the Creative Commons Attribution International License (CC BY 4.0).

http://creativecommons.org/licenses/by/4.0/

\section{(c) (i) Open Access}

\begin{abstract}
Science is the engine that drives the wheel of development. Consequently, there is a need for people to have faith in science and believe its facts and truths. This paper has looked into some of the definitions of what actually science is, and has highlighted some of the findings that science has concluded-the explanations offered in science. The main phenomena that have been tackled in this paper include rainfall and rainbows, earthquakes, lightning and thunders. Other facts that have been discussed include diseases, adaptation, natural selection, mutation, survival for the fittest and evolution. Faith and religion as well as beliefs have been mentioned too. The challenges facing the belief in science have been identified; how to overcome them, and where religion has been identified as the main obstacle in science's path. In general, this paper presents the overall view of science to the readers with the sole aim of enlightening people as to why they should actually believe in it, identifying the biggest challenge hindering furtherance of science ideas in men as well as offering ways that can help in overcoming them.
\end{abstract}

\section{Keywords}

Science, Religion, Evolution

\section{Introduction}

Science can be termed as today's teacher of all, as well as people's hope. Science doesn't lie. Science is facts. Most of the natural phenomena we observe and encounter in life such as earthquakes have been for long attributed to supernatural beings. People have dwelt in what their long-gone ancestors used to believe. They have refuted science without reasoning and in general, religion has turned them into rebels. People major in myths and superstitions. They believe that what is not direct from religion is evil and worthy of resistance. Evolution has 
been a big issue to religious men yet these are simple things that happen in everyday life. When a religious person hears survival for the fittest mentioned, they see as if God and other supernatural beings have been attacked. They view scientists as devil's tool to overthrow their faith. If one is willing to reason beyond faith and see what science offers, then many would realize how valuable this field is. They can decide for themselves and see that one can actually believe science and still be religious. People who have insight can understand that scientists are not irreligious; they also have faith. If you come to understand that science informs you that your mother gave birth to you, then you would understand why you should believe it and still go to heaven.

People can understand as to why it is not a hoax. They can see as to why it's not a myth. They can get to realize that it has solved mysteries, solved problems, informed, cautioned, and given hope to mankind. Science reveals and doesn't hide. It has corrected where people have erred. It is the "light" of the word. Without light, it is impossible to go far and to see clearly. It has opened up the minds of many and brought them to the high level of thinking ground where solutions to many challenges to human life have been offered. It is logical in nature, it's convincing and orderly. It is practical, truth and knowledge. It is a tool that simplifies life. Science is a real field that can build trust where there is none. The world rides on science and without it, it is a vehicle without wheels. Science is the world's pillar and without it, it can be likened to a house without a foundation.

However, science has faced a major setback in gaining popularity in the minds of many. The majority have not found enough reasons to believe in it. It hasn't found favour in the hearts of the majority despite its efforts in every aspect of life. But the question is, why? Why has it faced concrete walls to the hearts of the majority? Has it failed to achieve substantially in the eyes of these people? At this age, one can think that almost everyone, if not all, should be embracing science as a guide and light. What is barricading its path to reach many? Evidence is all around us on what it has done and on what it hasn't done yet. There is a lot to help everyone believe in it. People had believed for long that the earth is flat and the sun moves around it only to be proved otherwise by science [1]. Do people still need more evidence to believe in it? Is this not correcting erred people and misplaced mind? Is it not based on truth? Or the earth is still flat and stationary up to date for those who doubt science?

In conclusion, what science has done is plain to see for everyone and cannot be repudiated. It has presented evidence in every aspect of knowledge and has a foundation that can stand the test of times. However, there is a general resistance to these facts due to some obstacles that make it hard to penetrate its way into the minds and hearts of many. But there is still hope in overcoming the obstacles with time. Much has been done in teaching men the concepts in science but still much has not been achieved in winning men's approval. In fact, much in science is left to scientists. 


\section{Definition of Science}

There is no harm in understanding the definition of science first, from different perspectives, bearing in mind that there's no definite/single definition due to the fact that it is becoming complex each day (Yildirim C., 1970). In the paper, Yildirim has defined it as both a method of inquiry (composed of discovery and confirmation) and tested knowledge. Since it is in line with testing the knowledge thereof, then it cannot be a lie. There is nothing to hide about the knowledge and everything is open to anyone to test, discover, prove and confirm it. The aim is to help understand nature hence it must be convincing for one to understand its concepts. Understanding it results in demand for evidence in the face of claims accompanied by a genuine respect for facts. This indicates that even in the absence of a single or definite definition of science, one can gain a hint that it is based on evidence as well as facts, and not based on fables. What can make man not believe in what is based on evidence and facts? Since he has further defined it as a product and as a process, it's good see what each contains. As a product, it is a body of tested knowledge. This body is growing and the tested knowledge has factual statements and generalizations that have been confirmed. If they have been confirmed, then we are sure they aren't rumours. If the knowledge is tested, then it cannot be gossips. It is a complex method of inquiry when defined as a process, which means it can answer questions as well as can be used to gather information. This can help anybody who doubts anything about science to pose questions and obtain answers to the same. It is a way of searching for truth and information in order to add/gain knowledge. It is a way of carrying out investigations.

He has talked more about it as tentative, precise and consistent. Note these strong words used in describing it. All these explanations mean that it's based on experiments, accuracy and without contradictions. Further, he has given it a hazard definition as an attempt that turns beliefs as to world of facts into knowledge that is confirmed. See how he has reiterated that it is based on confirmation of knowledge. So, it is not to be taken without confirming and proving it. The fruits are reliable since it is through the scientific inquiry that reliable knowledge is obtained. Moving on with more explanations, Albert Einstein has it in 1959 work as a field that begins with experience as well as terminating in it [2]. And it's known to all that nothing is convincing more than experience since experience is the best teacher for all. In general, science is growing aims at explaining facts and the resulting coordination is unique and convincing [3]. According to Russel, he has put it that in the welter of conflicting fanaticisms, one of the few unifying forces is scientific truthfulness, the habit of basing our beliefs upon observations [4]. Therefore, it is based on truth and any belief in it must be upon observations. No one can force anybody to accept it without being convinced by its truth and observations since a person should develop genuine respect for facts as well as demanding evidence in case claims arise, Yildirim, 1970.

McColley G. in his 1937 has the definition from Oxford English Dictionary as 
a branch of study involving truths and facts that are systematic. It includes trustworthy methods aimed at discovering new truth within its domain [5]. Here, facts and truth are the main ingredients of science. Without truth and facts, the whole thing becomes something else and not science. This is the reason as to why the introduction has opened the first statements with a miscellaneous definition that suits science. The divers definitions are meant to help the reader understand fully with a wide scope of what science is. In the context of discovering new truth, one can see how science becomes light to men. The definition from the dictionary has included another statement where science is a whole body of regular or methodical observations. Now, if methodical observations is part of the definition, one is sure then that it deals with reality because whatever is observable is real and exists. Science from the astronomy perspective, in the same work, is that scientific facts/findings are as infallible as truth itself. See this definition; they are faultless, no weaknesses and without error. It's not fallacy. Such definition shows how reliable and superior science is. In general, the whole definition in McColley paper rotates around truth, facts and reality; that is science.

Although Kelso has attempted to define what science is, and his definition has been found with shortcomings, one cannot fail to point something beautiful out of his work, that it is characterized by an ability to predict real world occurrences [6], which means that this ability to predict gives one the confidence in trusting it. For example, the law of stars in astronomy, McColley in 1937. If there is law that stars are obeying, then one knows they can predict the next happening without doubts. Again, the law of gravity in which one is ever sure that whenever anything is thrown upwards, it will eventually come back to the ground. Another definition by Kelso is including the idea of deriving inductive generalizations from factual experience [7]. This implies that, the generalizations are from facts; the experiences are composed of or characterized by facts and hence are not myths. Now, Gensurowsky (1967) has tried to criticise and improve the work of Kelso whereby he has pointed out that the scientific sensations are registered from experience. This experience must be as a result of performing something, which makes science true. One cannot have experience from something that has not been performed or experience can't be gained without going through something. He has again included that the discrete judgement of many individuals will be integrated into a culturally determined consensus belief. So, the judgement is as a result of many and the belief is an agreement. This means that before anything is accepted and judged by many to reach a consensus, there must be a lot of testing and thinking in the line of reasoning as well as connecting so many things to see if they all agree with each other. In the end, the belief is born; out of reality, truth and experience.

\section{What Science Offers}

There's no need to go into much of the details in defining it based on different 
areas but at least one has gained an insight into what it entails, regardless of the area of study. But if it is truth, facts, consistent, reliable, provable, applicable, problem-solving, convincing and many more, then why do most people object its ideas? If asked, one would say that it has been left to scientists to believe in it, practice it and continue researching to add knowledge to what they already know. But where is the biggest blow when it comes to embracing its ideas? According to Yildirim Cemal (1970), he has pointed out that an effective scientific training is capable of making human beings more rational and less susceptible to unfounded beliefs. According to this, it's like the solution to the obstacles in accepting science is to provide effective training in science. So, the question is, stakeholders don't offer effective training to these majority who oppose science? One tends to differ with this because in Kenya, science subjects are mandatory to students since primary school and can be offered up to university level. Pupils are taught science and even how to make models such as pulleys, Stevenson screens, rain gauges, wind vanes and wind socks, mixing different colours to produce secondary colours, demonstrations in: sound transmission, siphons for air pressure, light travelling in straight lines through shadow and images formations, kaleidoscopes, rainbows and others. In general, a lot of practical has been offered to people; a lot of training and skills are on their fingertips. They have a lot of theoretical part too. In secondary schools, so much is offered to these people as students through Physics, Chemistry, Geography, Biology and others. At university level, they are not only taught, but find themselves in research itself whereby they apply scientific methods in their researches. And in many other ways do these people get to be trained in science. In all these, is one still talking of effective scientific trainings? There must be a real obstacle that needs to be tackled. Once that has been done, one can believe that science will be warmly welcomed into the hearts of many. It shall reign in the hearts and minds and lives of many; instead of being left to scientists only. It shall become the driving force to majority.

There is need to believe in science, especially now. Science has come a long way, trying to explain, convince and show in broad daylight, what has been going on around and in people, as well as far. It has explained almost everything in details, from the vicinity to the space. Before pointing out what could be the main barrier, it's in order to start by pointing out a few things that science has managed to "dissect" and demystify. Look at what physics explains happens to cause lightning and thunders. Simple and clear explanation is offered that it is caused by the discharge of atmospheric electrical charge. The Science News-Letter (1951) talks about how buildings can also cause these lightning and "absorb" thunders. The Empire State Building in New York is capable of initiating lightning strokes and can "steal" their thunders. This is attributed to its height which creates lightning and eliminates accompanying thunders. All these lightning are caused by accumulation of charges where the earth's charges get accumulated at the peak of the building and get attracted to the opposite charges in clouds and beat those of the clouds to the punch [8]. Friction is the main 
cause of the charges' accumulation and can be demonstrated to secondary school students using a rod and a clothing, a comb and pieces of papers, etc. Hasn't this been proved fully? It has.

Look at the explanations given about what causes earthquakes. The paper by McKerrow and Lambert (1973), though not concerned with causes of earthquakes, has focussed in details on some specific belts of earthquakes in determination of directions of descent of paleo-subduction zones. The conclusion from the paper is that in studying more examples of ancient plate margins, another method of achieving the same results would be obtained [9]. Earthquake, as the shaking of the earth, is caused by the slipping of the rocks along fault planes, volcanic action or any jar in the earth's crust (explosion of dynamite, landslides, falling of roof of a cavern, snapping of rocks under slight strains etc.) [10]. In volcanic action, when lava rises to the earth's surface, the rocks are broken and crushed into pieces enabling liquid rocks to be forced violently into the fissures. It's known how mountains such as Mt. Kenya are formed through volcanic eruptions. The volcanic activities are major ways of mountain formation, and this process of formation is still at work up to date (active mountains).

Tarr has mentioned how the process of mountain growth has been a major cause of earthquakes, in which rocks are in state of increasing strain, and after large masses of rock slide over other masses, earth trembling is felt. Huge masses of earth materials on other masses calls for readjustments of the materials for the sake of gaining balance and as a result, a minor or violent earth-shaking may be felt. Readjustments of earth's materials must occur whenever there is imbalance of weight. The earth rotates about its own axis resulting in flattening at the poles and bulging at the equator. This results in imbalance and calls for readjustments where earthquakes may result. Omori, 1906, has defined earthquake or trembling of the ground as vibrations or wave-movements propagated through rocks and soil. He has mentioned the cooling and contraction of earth as well as change in land and ocean material distribution which can be likened to volcanic activities and readjustments respectively that were mentioned by Tarr. But he has included the activities of mountain-making forces that produce folding or fracturing along zones. These result in falling or raising of materials, causing disturbances that are tremors or vibrations. Other causes include latitude variation due to rotation of earth (as mentioned by Tarr) and magnetic disturbances [11]. All these causes can be summarised into readjustments of earth's materials due to imbalances caused by divers forces such as volcanic actions, mountain-growth, magnetic forces, constructions and mining activities, rotation of earth etc.

Ice formation has been explained fully in the 1970 paper titled "Ice Formations" by Emery. A law is given on how bodies expand on increasing of temperature and contraction that follows reduction in heat. He has expounded on the congelation of water to ice through manipulation of temperatures [12]. Rain forms as a result of water vapour evaporation [13], which forms around particles by condensation (Coulier, 1875 and Aitken, 1881) [14] [15]. This idea of water 
particles forming around other particles, salt particles, that are relatively large, has been explained well by The Science News-Letter (1951) [16]. These processes of rain formation as well as ice are known and even taught in secondary school students as geography. They are logical and can be easily understood. There's no need to elaborate more on what has been done because no one can ever exhaust it.

\section{Challenges Facing Acceptance of Science and the Remedy}

After examining the few explanations given by scientists, it would be good revisit the question on why people still don't believe in science. As had earlier been mentioned, it's hard to believe that what is required is much more training in science since whatever has been offered is more than enough for one to be convinced. People are ever busy refuting science findings without basis and without examining the truth therein. The main obstacle in acceptance of science into the minds and hearts of majority is religion. The beliefs from religion that people have are the hindrances to the path of science. People prefer to walk in the paths of religion than those of science, without even thinking whether science has anything good to offer or not. If science presents anything to a religious man that is contrary to what they have been taught and believed, then that's a direct ticket to bury science in eternal grave. There is nothing science can offer to such people thereafter to help redeem itself. Once thrown and trampled under-feet, there is nothing to offer in return.

These majority do not refute the explanations given in science about the causes of and the forces behind earthquakes, rains, droughts and famines, diseases, machines, digestion systems, brain functioning, plant growth, reproductions, planets and other heavenly bodies including the sun, sea creatures in the coral reefs territory and how they work in harmony, etc. Write any articles, books, newspapers or such likes about all these areas and no one will object them. Even when it gives information on blood and blood systems, genes and DNA, no one will tell you it's a lie. Even when it mentions the movement of earth and moon and the causes of ocean tides, the force of gravity and the mathematics involved therein, the hot earth's core and volcanoes, the highest mountains and the longest rivers together with the deepest parts of the oceans, they won't alter a word against that. The information on why the dead sea is actually "dead", the latitudes and longitudes together with deserts (cold and hot), the adaptations of animals and plants in those deserts as well as other regions, the different types of climate on earth, the earth's tilt on its axis, comets that appear once after so many years, the meteorites that appear frequent in the earth's atmosphere, planets are spherical and the forces behind the spherical nature as well as the flattening at the poles, telescopes and microscopes and the principles behind their working, medicines and how they cure or prevent diseases, post-mortems on dead bodies and operations performed on people and animals, among others, is ever available to all, but no one will ever write an article and garbage such works 
in the name of religion or from religion's point of view.

What then do they reject in totality that makes them conclude that science cannot be trusted? What they fail to accept is what contradicts religion, namely, evolution. Evolution of man has dealt a heavy blow in making science to be rejected altogether. When each religious person gets information that man evolves and continues to evolve or even the origin of man from science point of view, yet they know from the religious perspective that supernatural beings performed creation to make man exist, then the information contradicts what they know. They feel their faith has been jeopardized and attacked the hard way in the process of developing such explanations. They feel that those who attempt to explain such are lost, misleading and are attacking the divine powers. They take it as contempt of the supernatural beings' authority and ability. They take it as if man has gone against the will of the holies and think he is cursed altogether. They say that anyone who attempts to offer a contradictory information is a religious sceptic. They feel you must be challenging God and gods as long as you are making any efforts towards such direction. Therefore, terms such as evolution of man, survival of the fittest, natural selection, adaptation in evolution and such likes are termed infamous, unacceptable, misplaced, disdaining to gods, blasphemous, and without a place in their hearts and minds as well as their lives. They are a form of knowledge that is injurious and should be avoided, rejected and even fought where possible to help curb its influence in others. To believe this, just take a moment and approach a staunch man in religion, offer them information on "origin of man" that is contrary to what religion has offered, and see for yourself. All they want to hear is that things remain unchanged since "creation" and everything is in control in the hands of the infallible beings.

One can find it worth looking into few authors' work on evolution and survival of the fittest to get a hint of what it entails. Natural selection is a process or a principle: preservation of the favoured individuals (animals or plants) in the struggle for life, evolution is a law while survival of the fittest is a result [17]. So, natural selection involves many individuals at first, then due to variations in individual characteristics and environment, all struggle for life resulting in elimination of the unfit and retention of the fit ones. Therefore, natural selection yields survival of the fittest. There are other terms used such as adaptation and mutation in the line of showing how changes can occur in individuals. In bacterial adaptation, changes persist while some reactions in some bacteria are attributed to mutation of genes [18]. Adaptations and mutation are meant to cause changes to individuals which eventually produce individuals that are different from others, no matter how small or big the differences are. The work has also pointed out that evolution is taking place at a quicker pace in tropics compared to temperate latitudes, which have different climates. Climate changes must bring about changes in individuals as they try to adapt to the new changes or to the new climate. And one can be sure of climate changes due to global warming and other causes, hence must be sure of changes in individual plants and ani- 
mals.

Charles Darwin, as part of developer of the work in evolution, has defined natural selection as preservation and rejection of favourable and injurious variations respectively. He has shed some light on what causes this scenario: that individuals are produced more than can be possibly supported or sustained and hence those with adaptive or better characteristics survive while the rest are eliminated [19]. Paul D. has outlined the history in the works of evolution and survival of the fittest, developed by Charles Darwin, Herbert Spencer, Richard Hofstadter, Gertrude Himmelfarb, James Rogers, Wallace, Alexander, Lyell and others [20]. The paper has discussed in length the phrases such as natural selection, survival of the fittest, fittest and fit, natural preservation, origin, variation among others. Pole Alistair and others performed an experiment with African wild dogs hunting impala to strongly demonstrate the survival of the fittest paradigm [21]. In the research, they demonstrated how the dogs actually predate on those impalas that are weak or have poor tactics in survival due to poor conditions such as poor health. For example, a healthy impala would be in a better position to escape while one that having leg issue may be captured easily. The mighty impala can fight back and escape the jaws of the dogs while the weak one would be miserably and helplessly damaged. So, both the predators and prey develop ways of surviving is their environment, and these ways are the traits meant to save them. The developed characteristics make them fit in their "home". The traits gained can change their physical appearance such as broadening of palms for human beings, thick and broader fingers, curved nails, webbed feet like those of beavers when they created their own aquatic environment (in the Bateson Patrick work of 2017 as will be seen later) among other traits.

In the journal The Science Teacher, another experiment has been performed involving lizards, birds and snakes to demonstrate how competition can lead to natural selection in a given population where sometimes the death by competitor is beneficial compared to the death by predator. In that research, there is repeated evidence of random death by predators with respect to running ability as well as body size traits. Again, densely populated regions with lizards led to strong natural selection which retained larger sized lizards with better running abilities. In that scenario, the lizards play for keeps and when things and times get tough, a room is not found for the meek [22]. This experiment, together with that of Pole and his colleagues, show the ability to perform evolutionary experiments in natural populations, The Science Teacher, 2010. One interesting thing that this Science Teacher journal has pointed out is how so many people are sceptical of evolutionary biology. These people perceive it as history that cannot be tested through experiments. They see it as myths and something that is not taking place in this current generation. They don't see it as a continuous process or activity that is currently at work or on going.

Today's sceptics of evolutionary biology should study the work of Patrick Bateson, 2017, that actually and literally opens the mind of the reader to see this area with simple examples. One of the examples is that of genetically identical 
individuals that may end up different due to environment cues. He has pointed out that if a system involving development is perturbed to a great extent, then, this can lead to unbelievable different outcome; where changes may kill an individual or make it adaptive. Again he has used a very strong statement, that if we come across a functioning device such as a car or a computer, that does not inform us anything about the evolution of the device, which is true to living things [23]. Hence, those who see human beings as they are currently cannot learn anything from that on how man has come a long way through evolution. But through study of facts and truths can inform you about history in development of human beings, computers, cars, planes, watches etc. There is a lot of beautiful truths and insights in this paper that can open up the minds of sceptics.

In general, the knowledge offered on evolution of man, animals and plants is the main cause of disbelieve in science, especially that of man, since it is mostly seen as a direct attack on religion, beliefs, holy scriptures, divine power and supernatural beings. It is considered as undermining the gods' ability and powers. It is the only part of science that is seen to go against the faith of many. Most who are not well versed with this version of science are not ready to be convinced otherwise; not willing to accept any knowledge that doesn't confirm that things are stable, unchanging and ever at rest since "creation". Write any scientific fact on "changes in man over time" and see the reactions, both written and verbal, from those who are religious. People held before that the lightning and thunders can only and must be caused by supernatural beings in the sky. They knew that that was the work and secrets of those beings who used them as weapons against wicked humans to demonstrate their anger and wrath. When science proved otherwise, no harsh reactions were directed towards science, and even today, both religious and unreligious are at peace with that knowledge. They believed in rains being caused by gods as well as droughts as blessings and curses respectively. But when science explained what happens for rain to happen and how some factors such as deforestation, global warming and others affect rain, how mountains, winds and others work towards formation of rains, there is no objection to that, from both religious and non-religious.

People knew that earthquakes are as a result of gods' anger and was an important tool in pursuing those who err in their sight. Later, science explained the causes and sources of earthquakes, tremors, and other forms of earth shakings. So far, no one has opposed these truths and facts from any religious point of view. Diseases, were believed to be a sharp, double-edged sword that is ever ready to delete the wicked from the face of the earth. They viewed anybody sick as one who is rejected by gods as well as one who has displeased them. It was seen as a total punishment from heavens and gods to those not at peace with these supernatural beings. Science has been explaining the causes of diseases not only in human beings but also in animals and plants. Both religious men and the rest have not written journals, papers, books, newspapers or such likes to reject what science has offered. Lightning and thunders, to men in the past, meant to- 
tal displeasure of gods with human beings. It was pure disapproval of their ways, thinking, and doings in the eyes of the holies. In fact, if they could be asked, they would explain how the holies could even cause thunders without lightning, simply because they had no idea on any of these and whatever happens. Later on, science came in and helped men understand what happens for lighting and thunders to occur. People got at peace with the explanations.

Rainbows were taken as a sign from heaven and that gods used rainbow to communicate with humans. It was thought to be something too special and full of mysteries to be understood by any man. Later, men learnt from science that these rainbows can only happen when there is rain and sunshine simultaneously. Demonstrations are even offered on how one can "create" a rainbow with water in sunshine or in the presence of light. How many papers have been written to refute this truth? None. How many have said they don't want to believe this because it is against religious teachings? No one. There's no need to go into details of the so many beliefs of the past that have been rectified through science because they are obvious and plain to the eyes of all. But one thing that should be mentioned is that, if any single phenomenon was so mysterious and shocking to early man, what about a combination of such several phenomena? Imagine a disease in the presence of an earthquake when it's raining where the rains are being accompanied by eye-blinding lightning and deafening thunders with a rainbow being visible in the horizon. How overwhelming is the scenario from the point of religion in those days? Things could only be taken too complicated for any man to even dare think of explaining or understanding what was happening. The whole thing is left to gods, supernatural beings and religion. Imagine the measure of anger that could be being portrayed by these gods? The wrath could be more than what is necessary to wipe out not only the crooked and wicked men on earth, but also the earth itself from its place. Such anger can only be immeasurable and without description.

Looking at what science has done, one is able to believe that actually, all the causes of these phenomena are the true causes because of the solutions being offered. One can become a believer in science easily without asking for more proves. Bateson P. has presented very simple observations that have a very great impact in the mind of a believer, and would be suggested that each person need test and experiment these simple experiments and see the facts by themselves, because experience in experiments is better than words. One of the solutions offered to us by science is the installation of lightning arrestors on houses and other high constructions such as communication boosters. These arrestors have barred the countless damages that would have resulted from lightning; ranging from construction demolitions to loss of lives, and people are aware of the principles behind lightning arrestors. This clearly demonstrates to them that the causes of lightning and thunders as presented in science is true and the solution offered is reliable. Another solution provided by science is that, found in the paper by Tarr R. S. in 1907, of strong buildings that have good foundations, taking 
great care in choosing the foundations' ground as well as erecting up earthquake-resisting structures.

Omori F. in his 1906 paper, mentioned about the same; good foundation-making that plays an important role in earthquake-proof construction of buildings and engineering structures, good construction sites such as high grounds and rocky areas. This careful construction has worked in saving buildings in case of even strong earthquakes. In the field of health, see how science has saved so many lives through the medicines that are either curative, preventive or painkillers. If the scientists had not understood the causes of diseases, how would they offer medicines that are meant for those maladies as well as reliable throughout the world, for all living things (humans, animals and plants)? One can see how reliable science has been and will continue to drive the world, whether majority believe it or not. These remedies that have been provided are as a result of understanding the causes of the phenomena. Careful study of the earthquakes, lightning, rains, diseases and others and their causes or the forces behind them, has helped scientists come up with ways of escaping the calamities that result from these phenomena. Now, to the religious and those who believe in other things and reject facts in science, it's good to meditate on the following questions: If supernatural powers are behind the lightning and thunders that kill people, animals and cause other destructions, how can a simple lightning arrestor bar their efforts? Why shouldn't those powers destroy the arrestors too to prove the men's work futile? If the earthquakes are due to the great anger of supernatural beings, why should rocky grounds and strong foundations in constructions save the buildings from their power? If diseases are as a result of curses from heavens to wicked beings on earth, why should medicines save lives of the wicked from the wrath of the heavens? In general, are lightning arrestors, strong foundations in buildings, medicines among others, stronger or wiser than the heavens, supernatural beings, religion, faith and others? Do the lightning arrestors and others have power over heavens and the super beings? If super beings are behind earthquakes and are meant to punish men, why then should they waste their efforts performing earthquakes at the bottom of sea where men don't live? Where do fossils that form oil in the deep parts of the earth come from? Fossils are deposits of animals' bodies and plants that died long time ago and finally form oil sources. Where do the plant remains, of over so many years, that form coal come from? The list of questions is endless.

How can we make science be accepted among many? More so, how can we overcome the barrier of religion for people to embrace the evolution concepts? To answer this question, one needs to comprehend two points. First, religion's contents are offered to people as early as they as still kids, long before they even join nursery schools. They have a lot of knowledge on gods, super beings, heavens and hells, superstition, faith etc. even before they get any grasp of numbers and words. As soon as they learn how to pronounce words, religion is presented to them. They are fed to them when their minds are still fresh and not fatigued 
with any kind of knowledge. Secondly, the evolution knowledge is presented to students at secondary school level. It is presented to people when their mind is already tired of education. At the time when they are fully fed up and not ready to be in class, when they have all sorts of knowledge in divers subjects, when they are comfortable with religious matters, that's when they are prepared to receive the natural selection and survival of the fittest subject. In fact, those who do not take history subject never get the chance to learn it in totality. Science presents its facts and truths on evolution of man to young people when they are comfortable in the comfort zones of religion. Science teaches primary school kids about how pulleys, gears and levers operate, pollination in plants and reproduction in man and animals, blood system and digestion in both animals and man, among other areas but opt to introduce evolution late, in secondary schools. It's good to note that we cannot teach an old dog new tricks. Offering the precious knowledge to them late in life is like wasting efforts and resources because all that results is stern rejection due to the already laid foundation from other sources of knowledge.

For the mind of an individual to comprehend the complexities that can be brought about by evolution in creatures, there's need to introduce the topics at the tender age of kids. Let religion and scientific facts of evolution compete as early as when the kid if receiving basics in lower levels of primary school, or even before they join nursery schools. Once an introduction is made at early stages in life, a strong foundation is laid that cannot be demolished whatsoever. All that would be required thereafter at frequent, regular and consistent intervals is to build upon the already laid foundation. The resistance would be greatly reduced almost to no resistance. An early trained mind doesn't get overwhelmed over simple issues and processes. A mind that is trained in one direction (religion, faith and super beings) is hard to be trained otherwise. A clogged and unopen mind doesn't accept anything contrary, even for comparison purposes. If we fail to offer the facts to them when they are very young, then, trying to do it at later stages in life would be an attempt to train an old dog new tactics. To get a good understanding of what all this means, let's consider the following: Suppose a person is preparing food but starts by boiling it in water only. How does it taste? Suppose that person does cooking of the same food but decides to fry it with onions only after boiling it in water. What is the taste? Suppose after boiling, he fries it with onions and oil. How does it taste? Suppose after boiling it, he fries it with onions, oil and adds salt. What is the taste now? Suppose the process of modification in cooking the same food continues with addition of other ingredients but adding one ingredient at a time, where the taste is tested each time an ingredient is added. In the end, a great deal of food is obtained with a great taste. The taste would be so good that no one can believe that the cook went through a long process before getting "there". Such simple example can serve to convince unbelieving man that a very complicated creature can be obtained as a result of evolution as creatures strive to survive in different conditions. 
Another scenario can be that involving a farmer and plants. Suppose a farmer starts by planting the crops on sand in desert. How are the yields? Suppose he plants the same crops in soil that is good in texture for roots to thrive. How are the yields? Suppose he plants them in the good soil but waters them regularly. How are the yields? Suppose he plants them in the good soil, waters regularly but adds manure. How is the yield? Suppose he does the same but increases sunshine. How is the yield? Suppose he does the same but uproots any form of weeds from the crops' field. How is the yield? Suppose he does the same but does the modifications where he does each of the modifications at a time; such as spraying, good spacing etc. Each time, he gets to compare the yields. In the end, the yield is so good and the crops are so healthy that no one can believe that the farmer came a long way to reach where he is currently in terms of farming and production. This is another example that can be used to demonstrate the complexities that can result from "evolution forces". From the foregoing examples, if uninformed man is allowed to taste the prepared food or get to see the farmer's yields, it would be hard for them to fail to relate the tasty food and the good harvest to supernatural beings, heavens, miracles, blessings or such. The mind of the learner at a tender age should be prepared and broadened to get to understand the complexities and mysteries that can be brought about by combined effects of different factors.

If a kid can retain much, if not all, of what religion offers, then why not that from science? To kids, there's need show them as early as possible that everyone in this world relies on science to improve their living conditions, to have good health, to move from one place to another, to communicate etc. It's good when a kid is informed that when being taken to hospital for immunizations with polios and others, then they are making use of science. When a kid gets into a car, they should be informed that they are "in" science. When they watch a television or listen to radios, they should know that that is science they are relying on. When they ask parents where they came from and where their mothers are "buying" babies from, let them be informed that science would explain to them, or let them be referred to science (such as, "According to science, we are evolving such that, it has taken so many millions of years for us to get to this stage. Science will inform you soon where I buy babies from." etc.) Let book publishers design short books and wall-charts with basics in evolution and images such as those in stages of man's development from ape-like creatures. Let a good foundation be laid in these kids and they shall not be easily swayed by unfounded beliefs. Let the seniors incorporate the ideas of evolution in short songs that kids are taught when at nursery school. And much more that can be done.

\section{Conclusions}

Adaptation, natural selection, mutation and evolution are ever happening each day. People are all sure that climate change is taking place today and as a result, creatures must adapt themselves, mutation can occur, natural selection takes its 
course and everything evolves with time. Evidence of extinct creatures such as dinosaurs points out that there is possibility that so many other creatures and plants have gone extinct in the lineage of evolution while other creatures and plants have come to exist. Extinction of some groups of people has occurred too, such as those cities that are completely destroyed in great earthquakes and volcanoes, and even families where a road accident may wipe out all of the family members. People even talk about natural selection unknowingly when they mention the survival of people after a calamity such as accident, war, floods, earthquakes, drought, etc. Things are ever changing and we cannot stick to the belief that things remain unchanged since "creation". The earth is ever adjusting itself to contain the ever-changing distribution of weight on it, people adjust themselves when loaded heavily on one side, weighing balances adjust themselves whenever load is placed on them on one side, buildings collapse if overloaded or weakened on one side, etc. Since everything adjusts itself when disturbed to regain balance, even so do creatures and plants adjust themselves to cope with the ever-changing circumstances and environments. Some gain new traits to survive, while others perish.

Evolution is brought about by so many combined factors whose effects are felt through improved creatures and extinct ones. The combined effects can produce a greatly complicated creature such as what we see today in animals, plants and human beings. The complexities cannot be understood how they came about if one has no understanding in natural selection. There are so many simple experiments and examples that can be used to help understand this process. After gaining a good grasp of what natural selection is, one is able to comprehend what a creature can result "when so many factors combine over such a long time in history of evolution and in such a manner". Up to date, it's only science in evolution that can offer explanations as to why we are all different though we are human beings. It can offer reliable explanations as to why we have different races in this world, why we are not identical though we are of the same family, same tribe and in the same region. There is a need to put effective efforts in educating people on science, more so, evolution. The aim should be to target young people, kids, when their minds are fresh and not yet "overloaded". Science is true, genuine, full of facts, convincing, correcting, reliable, changing the world, light, and so much more. It's time to believe and rely on it.

\section{Conflicts of Interest}

The author declares no conflicts of interest regarding the publication of this paper.

\section{References}

[1] Yildirim, C. (1970) Towards an Understanding of Science. Journal for General Philosophy of Science, 1, 104-118. https://doi.org/10.1007/BF01801444

[2] Einstein, A. (1959) Philosopher, Scientist. Harper Torch Books, New York, 137.

[3] Einstein, A. (1940) Considerations Concerning the Fundaments of Theoretical 
Physics. Science, 91, 487-491. https://doi.org/10.1126/science.91.2369.487

[4] Russell, B. (1946) History of Western Philosophy. Allen and Unwin, London, 864.

[5] McColley, G. (1937) Bishop John Wilkins and the Definition of Science. Isis, 27, 261-263. https://doi.org/10.1086/347245

[6] Gensurowsky, W. (1967) Definition of Science: Comment. Journal of Farm Economics, 49, 222-224. https://doi.org/10.2307/1237084

[7] Kelso, M.M. (1965) A Critical Appraisal of Agricultural Economics in the Mid-Sixties. Journal of Farm Economics, 47, 1-16. https://doi.org/10.2307/1236148

[8] (1951) Nature Ramblings: Humming-Bird. The Science News-Letter, 60, 28. https://doi.org/10.2307/3929384

[9] McKerrow, W.S. and Lambert, J. (1973) Deep Earthquakes, Surface Subsidence, and Mantle Phase Changes. The Journal of Geology, 81, 157-175. https://doi.org/10.1086/627832

[10] Tarr, R.S. (1907) The Cause of Earthquakes. The North American Review, 184, 494-507.

[11] Omori, F. (1906) On Seismic Motion and Some Relations of Earthquakes to Other Phenomena. Publications of Astronomical Society of the Pacific, 18, 235-241. https://doi.org/10.1086/121688

[12] Emery, H.L. (1970) Ice Formations. Scientific American, 22, 204.

[13] Hobbs, P.V. (1989) Research on Clouds and Precipitation: Past, Present, and Future, Part I. Bulletin of the American Meteorological Society, 70, 282-285. https://doi.org/10.1175/1520-0477-70.3.282

[14] Coulier, P.J. (1875) Note sur une Nouvelle Propriete de l'Air. Journal de Pharmacie et de Chimie, 22, 165-173, 254-255.

[15] Aitken, J. (1881) On Dusts, Fogs and Clouds. The Royal Society of Edinburgh, 30, 337-368. https://doi.org/10.1017/S0080456800029069

[16] (1951) New Rain Theory. The Science News-Letter, 59, 116. https://doi.org/10.2307/3928604

[17] Howerth, I.W. (1917) Natural Selection and the Survival of the Fittest. The Scientific Monthly, 5, 253-257.

[18] Olson, E.C. (1954) Experimental Biology and Evolution. Evolution, 8, 84-87. https://doi.org/10.1111/j.1558-5646.1954.tb00113.x

[19] Darwin, C. (1964) On the Origin of Species, Facsimile of First Edition. Harvard University Press, Cambridge, 80-81. https://doi.org/10.2307/j.ctvjf9xp5

[20] Paul, D.B. (1988) The Selection of the "Survival of the Fittest". Journal of the History of Biology, 21, 411-424. https://doi.org/10.1007/BF00144089

[21] Pole, A., et al. (2003) African Wild Dogs Test the "Survival of the Fittest" Paradigm. Proceedings of the Royal Society B: Biological Sciences, 270, S57. https://doi.org/10.1098/rsbl.2003.0011

[22] The Science Teacher (2010) Survival of the Fittest.

[23] Bateson, P. (2017) Adaptability in Evolution. In: Bateson, P., Ed., Behaviour, Development and Evolution, Open Book Publishers, Cambridge, 1-110. https://doi.org/10.11647/OBP.0097.10 